\title{
Profil Kegawatdaruratan Pasien Berdasarkan Start Triage Scale di Instalasi Gawat Darurat RSUP Prof. Dr. R. D. Kandou Manado Periode Januari 2018 sampai Juli 2018
}

\author{
${ }^{1}$ Muhammad F. Bazmul \\ ${ }^{2}$ Eka Y. Lantang \\ ${ }^{2}$ Barry I. Kambey
}

\author{
${ }^{1}$ Program Studi Pendidikan Dokter Fakultas Kedokteran Universitas Sam Ratulangi Manado \\ ${ }^{2}$ Bagian Anestesiologi dan Terapi Intensif RSUP. Prof. DR. R. D. Kandou Manado \\ Email: mfbazmul@gmail.com
}

\begin{abstract}
Emergency Department provides first emergency services to patients with threats of death and disability in an integrated manner involving multi disciplines. Patients who come to the Emergency Department are always assessed as 3 priorities, namely priorities 1, 2 and 3. Priority 1 is case/disease with life-threatening emergency or severe emergency; Priority 2 is case/disease with mild emergency; and Priority 3 is non-emergency case/disease. This study was aimed to obtain the Triage profile of patients at Emergency Department of Prof. Dr. R. D. Kandou Hospital Manado. This was a retrospective descriptive study using patients' medical records. Samples were all patients treated at the Emergency Department of Prof. Dr. R. D. Kandou Hospital from January 2018 until July 2018. The results showed that there were 19,229 patients as samples. Based on sex, most patients were male, meanwhile based on age most were 51-70 years, with the highest number of patients in March 2018. There were 6,913 patients (35.9\%) in the orange or emergency category (Priority 2) and 6,130 patients (31.8\%) in the yellow category (Priority 3). Conclusion: Based on the Start Triage in Emergency Department, the majority of patients were in Priority 2 category, followed by Priority 3 category.
\end{abstract}

Keywords: Emergency Department, Start Triage

\begin{abstract}
Abstrak: Instalasi Gawat Darurat (IGD) memberikan pelayanan pertama yang bersifat emergency pada pasien dengan ancaman kematian dan kecacatan secara terpadu dengan melibatkan multi disiplin ilmu. Pasien yang datang di IGD selalu dinilai kegawatannya menjadi 3 prioritas, yaitu prioritas 1, 2, dan 3. Prioritas 1 yaitu kasus/penyakit dengan kegawatdaruratan yang mengancam jiwa atau gawat darurat berat. Prioritas 2 untuk kasus/penyakit dengan gawat darurat ringan. Prioritas 3 untuk kasus/penyakit yang bukan gawat darurat. Penelitian ini bertujuan untuk mengetahui profil skala Triase pasien yang masuk di IGD RSUP Prof. Dr. R. D. Kandou Manado. Jenis penelitian ialah deskriptif-retrospektif, menggunakan data rekam medis pasien. Sampel penelitian ialah seluruh pasien yang dirawat di IGD RSUP Prof. Dr. R. D. Kandou Manado periode Januari 2018 sampai Juli 2018. Hasil penelitian mendapatkan data pasien yang masuk ke Ruang IGD RSUP Prof. Dr. R. D. Kandou Manado terhitung sejak Januari hingga Juli 2018 sebanyak 19.229 orang. Distribusi pasien terbanyak berdasarkan jenis kelamin ialah laki-laki, dan berdasarkan usia ialah 51-70 tahun, dengan jumlah pasien terbanyak pada bulan Maret 2018. Pasien IGD terbanyak ialah kategori jingga yaitu emergency (Prioritas 2) berjumlah 6.913 orang $(35,9 \%)$ serta kategori kuning (Prioritas 3) berjumlah 6.130 orang $(31,8 \%)$. Simpulan: Berdasarkan skala Triase di IGD, pasien terbanyak ialah Prioritas 2, disusul dengan Prioritas 3.
\end{abstract}

Kata kunci : Instalasi Gawat Darurat, skala Triase 
Perkembangan ilmu dunia kedokteran saat ini telah semakin maju. Di Manado sendiri telah banyak didirikan rumah sakit yang memanfaatkan perkembangan teknologi yang ada. Akan tetapi perkembangan di dunia kedokteran bukan berarti membuat tenaga medis meninggalkan metodemetode lama yang masih efektif untuk digunakan.

Salah satu teknik yang efektif untuk digunakan khususnya dalam penanganan kegawatdaruratan ialah skala Triase. Gawat darurat adalah suatu keadaan penderita yang memerlukan pemeriksaan medis segera, dan bila tidak dilakukan akan berakibat fatal bagi penderita. Instalasi Gawat Darurat (IGD) adalah salah satu unit di rumah sakit yang harus memberikan pelayanan darurat kepada masyarakat yang menderita penyakit akut dan mengalami kecelakaan sesuai dengan standar. ${ }^{1,2}$

Angka kunjungan kasus kegawatdaruratan bervariasi dalam jumlah kasus pada berbagai pusat kesehatan di berbagai negara. Berdasarkan suatu observasi yang dilakukan Pleh Wier tercatat lebih dari 120 juta kasus kegawatdaruratan pada tahun 2009 di Amerika. ${ }^{3}$ Angka ini terus mengalami peningkatan dari tahun 1991 sebanyak 44\% hingga tahun $2010 .{ }^{4} \mathrm{Di}$ Inggris tercatat sebanyak 41 juta kasus kegawatdaruratan dalam periode tahun 2010 hingga 2013, berdasarkan suatu observasi yang dilakukan oleh Quality Watch Research Program. ${ }^{5}$ Berdasarkan data Direktorat Jenderal Bina Pelayanan Medik Depkes pada tahun 2007, jumlah rumah sakit di Indonesia sebanyak 1.319 yang terdiri atas $1.033 \mathrm{RSU}$ dengan jumlah kunjungan ke RSU sebanyak 33.094.000, sementara data kunjungan ke IGD sebanyak 4.402.205 (13,3\% dari total seluruh kunjungan di RSU), dari jumlah seluruh kunjungan IGD terdapat $12,0 \%$ berasal dari pasien rujukan. ${ }^{6}$

Pasien yang masuk ke IGD rumah sakit tentunya butuh pertolongan yang cepat dan tepat. Untuk itu perlu adanya standar dalam memberikan pelayanan gawat darurat sesuai dengan kompetensi dan kemampuannya sehingga dapat men- jamin suatu penanganan gawat darurat dengan response time yang cepat dan penanganan yang tepat. Kesemuanya ini dapat dicapai antara lain dengan meningkatkan sarana, prasarana, sumber daya manusia dan manajemen Instalasi Gawat Darurat rumah sakit sesuai standar. ${ }^{6}$ Instalasi Gawat Darurat (IGD) melayani pertolongan pertama pada kasus/penyakit yang tergolong emergency, yaitu melakukan diagnosis dan pengobatan pada penyakit akut dan cedera yang memerlukan tindakan segera. Pasien yang datang di IGD selalu dinilai kegawatannya menjadi 3 prioritas, yaitu prioritas 1, 2 dan 3. Prioritas 1 yaitu kasus/penyakit dengan kegawatdaruratan yang mengancam jiwa atau gawat darurat berat. Prioritas 2 untuk kasus/ penyakit dengan gawat darurat ringan. Prioritas 3 untuk kasus/penyakit yang bukan gawat darurat. Pasien dengan prioritas 1 menjadi pilihan pertama petugas untuk mendahulukan pelayanan. Pasien dengan prioritas 2 ditangani setelah pasien prioritas 1 selesai ditangani. Karena itu perlu pengertian dan kesabaran dari pasien atau pengantarnya. Prioritas 1, 2, dan 3 ditentukan oleh dokter IGD sesuai dengan derajat kegawatannya. Agar tidak mengganggu petugas dalam melakukan pertolongan pasien, maka hanya satu atau dua orang pengantar diperbolehkan masuk..$^{711}$

Instalasi Gawat Darurat (IGD) merupakan tempat pelayanan pertama bagi pasien yang datang ke rumah sakit, mulai dari pasien gawat darurat berat sampai pasien gawat darurat ringan. Penggunaan skala Triase masih sangat penting untuk digunakan agar bisa meminimalisir risiko terjadinya kesalahan pada pertolongan pertama di IGD. Pentingnya skala Triase berbanding terbalik dengan praktek di lapangan. Penelitian ini bertujuan untuk mendapatkan profil derajat kegawatdaruratan pasien berdasarkan skala Triase di Instalasi Gawat Darurat RSUP Prof. Dr. R. D. Kandou Manado.

\section{METODE PENELITIAN}

Jenis penelitian ini ialah deskriptif retrospektif. Populasi penelitian ini ialah 
seluruh pasien yang masuk di IGD RSUP Prof. Dr. R. D. Kandou Manado. Data yang digunakan yaitu data rekam medik IGD periode Januari 2018 sampai dengan Juli 2018 dan yang memenuhi kriteria inklusi.

\section{HASIL PENELITIAN}

Tabel 1 memperlihatkan data pasien dengan jenis kelamin laki-laki sebanyak 9.921 orang $(51,7 \%)$ dan pasien dengan jenis kelamin perempuan sebanyak 9.297 $(48,3 \%)$.

Tabel 1. Karakteristik pasien berdasarkan jenis kelamin

\begin{tabular}{ccc}
\hline $\begin{array}{c}\text { Jenis } \\
\text { kelamin }\end{array}$ & $\begin{array}{c}\text { Frekwensi } \\
(\mathbf{n})\end{array}$ & $\begin{array}{c}\text { Persentase } \\
(\mathbf{\%})\end{array}$ \\
\hline Laki-laki & 9.932 & 51,7 \\
Perempuan & 9.297 & 48,3 \\
Total & 19.229 & 100 \\
\hline
\end{tabular}

Tabel 2 memperlihatkan bahwa berdasarkan usia, yang terbanyak ialah kelompok usia 51-70 tahun, dan yang paling sedikit ialah kelompok usia 11-15 tahun.

Tabel 3 memperlihatkan bahwa jumlah pasien IGD terbanyak pada bulan Maret 2018 dengan jumlah 3072 orang, dan yang paling sedikit ialah pada bulan Juni 2018.

Tabel 4 menunjukkan bahwa pasien terbanyak yang masuk IGD ialah pasien dengan kode triase warna jingga berjumlah 6.913 orang, diikuti oleh warna kuning sebanyak 6.130 orang, kemudian warna hijau dan putih sebanyak 5.432 orang, kemudian warna merah sebanyak 768 orang.

Tabel 2. Karakteristik pasien berdasarkan usia

\begin{tabular}{ccc}
\hline $\begin{array}{c}\text { Usia } \\
\text { tahun) }\end{array}$ & $\begin{array}{c}\text { Frekuensi } \\
\text { (n) }\end{array}$ & $\begin{array}{c}\text { Persentase } \\
(\%)\end{array}$ \\
\hline $0-1$ & 984 & 3,9 \\
$2-5$ & 1029 & 5,4 \\
$6-10$ & 984 & 3,9 \\
$11-15$ & 871 & 3,2 \\
$16-20$ & 1128 & 5,4 \\
$21-30$ & 1692 & 10,8 \\
$31-50$ & 4073 & 23,8 \\
$51-70$ & 5927 & 33,3 \\
$71-90$ & 1888 & 9,7 \\
$91-99$ & 13 & 0,08 \\
Total & 19.229 & 100 \\
\hline
\end{tabular}

Tabel 3. Distribusi jumlah pasien yang masuk di IGD per Januari - Juli 2018

\begin{tabular}{ccc}
\hline Bulan & $\begin{array}{c}\text { Rerata } \\
\text { pasien/hari }\end{array}$ & Total \\
\hline Januari & 91 & 2825 \\
Februari & 88 & 2738 \\
Maret & 99 & 3072 \\
April & 93 & 2777 \\
Mei & 90 & 2799 \\
Juni & 82 & 2457 \\
Juli & 83 & 2561 \\
\hline
\end{tabular}

Tabel 4. Estimasi Distribus pasien berdasartan pengkajian Triase di IGD

\begin{tabular}{llllllll}
\hline Kategori & Januari & Februari & Maret & April & Mei & Juni & Juli \\
\hline Merah (resusitasi) & 112 & 108 & 127 & 110 & 111 & 98 & 102 \\
Jingga (emergency) & 1.016 & 983 & 1106 & 997 & 1008 & 883 & 920 \\
Kuning (urgent) & 899 & 873 & 980 & 885 & 895 & 783 & 815 \\
Hijau/Putih (non urgent) & 798 & 774 & 869 & 785 & 789 & 693 & 724 \\
Total & 2825 & 2738 & 3072 & 2777 & 2799 & 2457 & 2561 \\
\hline
\end{tabular}

\section{BAHASAN}

Profil Kegawatdaruratan RSUP Prof. Dr. R. D. Kandou Manado

Skala triase yang digunakan RSUP Prof. Dr. R. D. Kandou Manado ialah Simple Triage and Rapid Treatment yang dipadukan dengan penggunaan 5 kategori warna. Kategori warna yang digunakan ialah merah untuk resusitasi, jingga untuk emergency, kuning untuk urgent, dan hijau untuk non urgent, serta putih untuk false alarm. Hasil penelitian ini mendapatkan pasien IGD terbanyak berada pada kode jingga sebanyak 6.913 orang, diikuti oleh 
warna kuning sebanyak 6.130 orang, warna hijau dan putih sebanyak 5.432 orang, serta warna merah sebanyak 768 orang. Berdasarkan usia pasien yang masuk ke IGD didapatkan bahwa 8.268 atau $43 \%$ pasien yang masuk di IGD berusia di atas 50 tahun.

Dalam proses pengumpulan data didapatkan kurangnya kelengkapan pendataan terkait pelaksanaan triase di IGD RSUP Prof. Dr. R. D. Kandou Manado yang menyulitkan peneliti dalam mengembangkan dan menggambarkan profil derajat kegawatdaruratan pasien berdasarkan start triase di IGD RSUP Prof. Dr. R. D. Kandou Manado dengan lebih detail. Tidak adanya data yang langsung dilengkapi dengan kode warna maupun skala yang diberikan pada pasien saat pelaksanaan triase membuat peneliti hanya berpedoman terhadap catatan jumlah pasien setelah masuk ke bagian-bagian di RSUP Prof. Dr. R. D. Kandou Manado.

Penelitian oleh Nonutu et $\mathrm{al}^{12}$ pada tahun 2015 melaporkan bahwa tingkat ketepatan pelaksanaan Triase di RSUP Prof. R. D. Kandou Manado memiliki hubungan dengan jumlah pasien yaitu semakin banyak pasien yang datang semakin menurun ketepatan pelaksanaan Triase. Penelitian dari Nonutu merupakan penelitian lapangan dengan mengobservasi pelaksanaan Triase pada 136 pasien di IGD. Mengacu pada hasil penelitian Nonutu, peneliti semakin menyadari pentingnya pendataan yang lebih detail sehingga dapat menjadi bahan koreksi dan evaluasi pada pihak IGD agar dapat menjaga kualitas pelayanan pada pasien. Instalasi Gawat Darurat merupakan gerbang utama rumah sakit yang selama 24 jam dapat melayani pasien. Apabila terjadi peningkatan drastis pada jumlah pasien melalui unit ini, akan terjadi kepadatan (overcrowding) di IGD. Oleh karena itu, diperlukan metode Triase untuk menentukan kategori pasien yang menjadi prioritas sejak awal kedatangan. Ketepatan dalam menentukan prioritas pasien membantu menjaga kualitas pelayanan agar dapat lebih difokuskan dalam menangani kasus yang benar-benar gawat darurat, serta mengalihkan kasus yang tidak gawat atau lebih ringan ke fasilitas dan pelayanan kesehatan yang sesuai.

Pada penelitian ini didapatkan bahwa pihak RSUP Prof. Dr. R. D. Kandou Manado tidak memiliki pencatatan data yang cukup tertata terkait pelaksanaan Triase terhadap pasien sehingga cukup sulit untuk melakukan analisis yang lebih mendalam terhadap profil derajat kegawat daruratan pasien yang masuk ke IGD.

\section{SIMPULAN}

Berdasarkan hasil penelitian ini dapat disimpulkan bahwa IGD RSUP. Prof . Dr. R. D. Kandou Manado menggunakan START Triase yang dipadukan dengan 5 kategori warna triase. Pasien terbanyak masuk ke IGD dalam kategori warna jingga atau emergency dan kategori warna kuning. Pasien dengan kategori warna hijau dan putih sulit untuk dikaji lebih lanjut karena data yang digabung dalam satu buah buku arsip.

\section{SARAN}

Kelengkapan pengisian data di Bagian Rekam Medik dan Instalasi Gawat Darurat sangat diperlukan guna menunjang pendekatan yang lengkap, akurat dan informatif sehingga dapat meningkatkan penanganan dan dapat digunakan sebagai acuan

\section{DAFTAR PUSTAKA}

1. Nasution A. Instalasi Gawat Darurat. Universitas Sumatra Utara. 2011. Available from: http://repository. usu.ac.id.

2. Limantara R, Herjunianto, Roosalina A. Faktor-faktor yang mempengaruhi tingginya angka kematian di IGD rumah sakit. Jurnal Kedokteran Brawijaya. 2015;28(2):201.

3. Centers For Disease Control and Prevention. Emergency Department Visits and Proximity to Patients' Residences, 2009-2010. 2015. Available from: http://www.cdc.gov/nchs/fastats/emer gency-department.htm.

4. Blunt I. Focus on: A\&E Attendances 
Qualitywatch. Nuffield Trust. July 24, 2014.

5. Stein L. Mass Casuality Triage. Okla Nurse. 2008;53(2):18-21.

6. Kesehatan Republik Indonesia. Standar Instalasi Gawat Darurat (IGD) Rumah Sakit. 856/Menkes/SK/IX/ 2009.

7. RSUD Tarakan Jakarta. Instalasi Gawat Darurat, Layanan Penunjang. Available from: www.rstarakan jakarta.com.

8. Fakultas Kedokteran Universitas Sumatera Utara. Blok Emergency Medicine. Buku Panduan Mahasiswa. 2009;1.
9. Triage. Available from https://www. academia.edu/4293016/TRIAGE.

10. Fadhilah IQ. Triase Gawat Darurat Lengkap PPGD. Informasi kesehatan Pertolongan Pertama. 2014. Available from: www.idmedis.com.

11. S.T.A.R.T (Simple Triage and Rapid Treatment). Available from: www. emsconedonline.com.

12. Nonutu PT, Mulyadi, Malara R. Hubungan jumlah kunjungan pasien dengan ketepatan pelaksanaan Triase di Instalasi Gawat Darurat RSUP Prof. Dr. R. D. Kandou Manado. Jurnal Keperawatan. 2015;3(2):1-6. 